\title{
Regional Legislatures and National Lawmaking
}

\author{
Ben Noble \\ Lecturer in Russian Politics \\ University College London, School of Slavonic and East European Studies
}

SSEES-UCL,

Gower Street,

London

WC1E 6BT

Tel.: 02076791451

Email: benjamin.noble@ucl.ac.uk

Twitter:@Ben_H_Noble

ORCID ID: 0000-0002-6844-8886

12 February 2018

Word count: 1,290

\begin{abstract}
Recent work has noted the supposedly 'exceptional' constitutional authority of sub-national legislatures in Mexico to introduce legislative initiatives into the national congress. Rather than a mechanism unique to Mexico, however, this debate article notes other states' constitutions with similar provisions, drawing on data from the Comparative Constitutions Project, as well as a new dataset on lawmaking in the Russian Federation. The article calls for a new collaborative research agenda to explore the involvement of sub-national legislatures in national-level lawmaking.
\end{abstract}

\section{Keywords}

Sub-national legislatures; lawmaking; constitutions; Mexico; Russia. 
When we think of bill initiation in national legislatures, we naturally think of federal actors as the protagonists. A recent article in this journal challenges this picture. Ugues, Vidal, and Bowler (2017) analyse the national lawmaking activity of sub-national legislatures in modern-day Mexico. Beyond describing the frequency, substance, timing, and fates of initiatives introduced by regional assemblies into the national congress, the authors also look at 'which factors affect the probability of presenting a state-led initiative' (Ugues, Vidal, and Bowler, 2017, p. 1). The article is, therefore, a very welcome development in a field that 'has traditionally restricted attention to national assemblies' (Downs 2014: 609).

How widespread is this constitutional authority of sub-national legislatures to introduce bills into national legislatures? Ugues, Vidal, and Bowler $(2017: 1,3)$ claim that the authority to introduce bills into the federal congress is 'a right featured exclusively in Mexico' - 'this important lawmaking role is unique to Mexico'. ${ }^{1}$

They are wrong. Contrary to this claim of Mexican exceptionalism, there is evidence that this 'peculiar mechanism of federal lawmaking' (Ugues, Vidal, and Bowler 2017: 2) is found in other states. In the Russian Federation, for example, article 104.1 of the 1993 Constitution states that 'legislative (representative) bodies of the subjects of the Russian Federation' have the 'power to initiate legislation' in the State Duma - the lower chamber of the Federal Assembly. ${ }^{2}$

\footnotetext{
${ }^{1}$ Just before the latter statement they note, however, that a 'federal lawmaking role for subnational governments also exists in Spain, where the Spanish autonomous communities have similar rights' (Ugues, Vidal, and Bowler 2017: 3). Although not mentioned in the article, the authors differentiate the Spanish and Mexican cases regarding whether sub-national assemblies can introduce initiatives directly to the national parliament or not (personal communication with the corresponding author, 21 November 2017).

2 An English-language version of the 1993 Russia Constitution is available here:

http://www.constitution.ru/en/10003000-01.htm.
} 
Russian sub-national legislatures make great use of this constitutional authority. Figure 1 presents data on the number of bills introduced by regional parliaments into the State Duma by year.

\section{[Figure 1 around here]}

This activity compares favourably to other actors with the right of Duma bill introduction. Between the spring sessions of 2012 and 2015, Russian regional legislatures were second only to Duma deputies regarding the total number of initiative introductions, surpassing even the government (Noble and Schulmann, 2018: 59). This is even more surprising in light of the fact that the vast majority of these initiatives fail to become law. For example, in 2012, although regional assemblies introduced 326 bills, in the same year only 20 bills sponsored by regional assemblies became law. ${ }^{3}$

Which other states include such a provision? The Comparative Constitutions Project (CCP) - an initiative to collect, structure for comparison, and analyse features of constitutional texts provides a unique dataset, which can be used as a first step in gauging the geographical and temporal distribution of constitutional features. Variable 263 of the dataset contains information supplied by country experts in response to the question, 'Who does the constitution specify can initiative general legislation?'. Response 96 is 'other', with experts requested to supply further details in the comments section (the 'leg_in_comments' variable). Of the 15,567 country-years in the dataset, 2,766 include information on 'other' sponsors of legislative initiatives in national legislatures (beyond the categories of heads of state, government, members of the upper and lower chambers, and so on). Of these 2,766 entries, 337 include references to sub-national bodies. Figure 2 shows the 17 countries that are coded as providing constitutional authority for sub-national

\footnotetext{
${ }^{3}$ Author's own calculation from the dataset compiled by the author, drawn from information on the State Duma's online law-making archive (available here: http://api.duma.gov.ru/).
} 
assemblies to introduce legislation into their respective national legislatures (further details in table 1).

[Figure 2 around bere]

For example, the Ali Mejlis (Supreme Assembly) of the Nakhichevan Autonomous Republic of Azerbaijan has the authority to introduce bills to the Milli Majlis (National Assembly) of Azerbaijan; Swiss cantons have the authority to introduce bills to the Swiss Federal Assembly; regional congresses in Peru had the authority to submit bills to the Congress of Peru; and the Assembly of People's Deputies of the Gorno-Badakhshan Autonomous Region of Tajikistan has the authority to introduce bills to the Majlisi Oli (Supreme Assembly) of Tajikistan. Rather than being restricted to Mexico, therefore, this constitutional provision is present across a range of countries.

There are clear problems, however, with the CCP data. Most obviously, certain country cases are incorrectly excluded, including the Russian Federation and Spain. Such omissions and inaccuracies are to be expected for an ambitious data-collection exercise such as the CCP, particularly when this particular constitutional provision is not the primary focus of analysis.

However, this first-step analysis does underscore a clear lacuna: an accurate and complete record of sub-national legislatures' authority to introduce national-level legislative initiatives. Such a dataset would be of interest to scholars working in a variety of fields, including federalism, constitutional law, and comparative lawmaking processes. 


\section{Figures}

Figure 1: Total number of bills introduced by Russian regional legislatures into the State Duma by year.

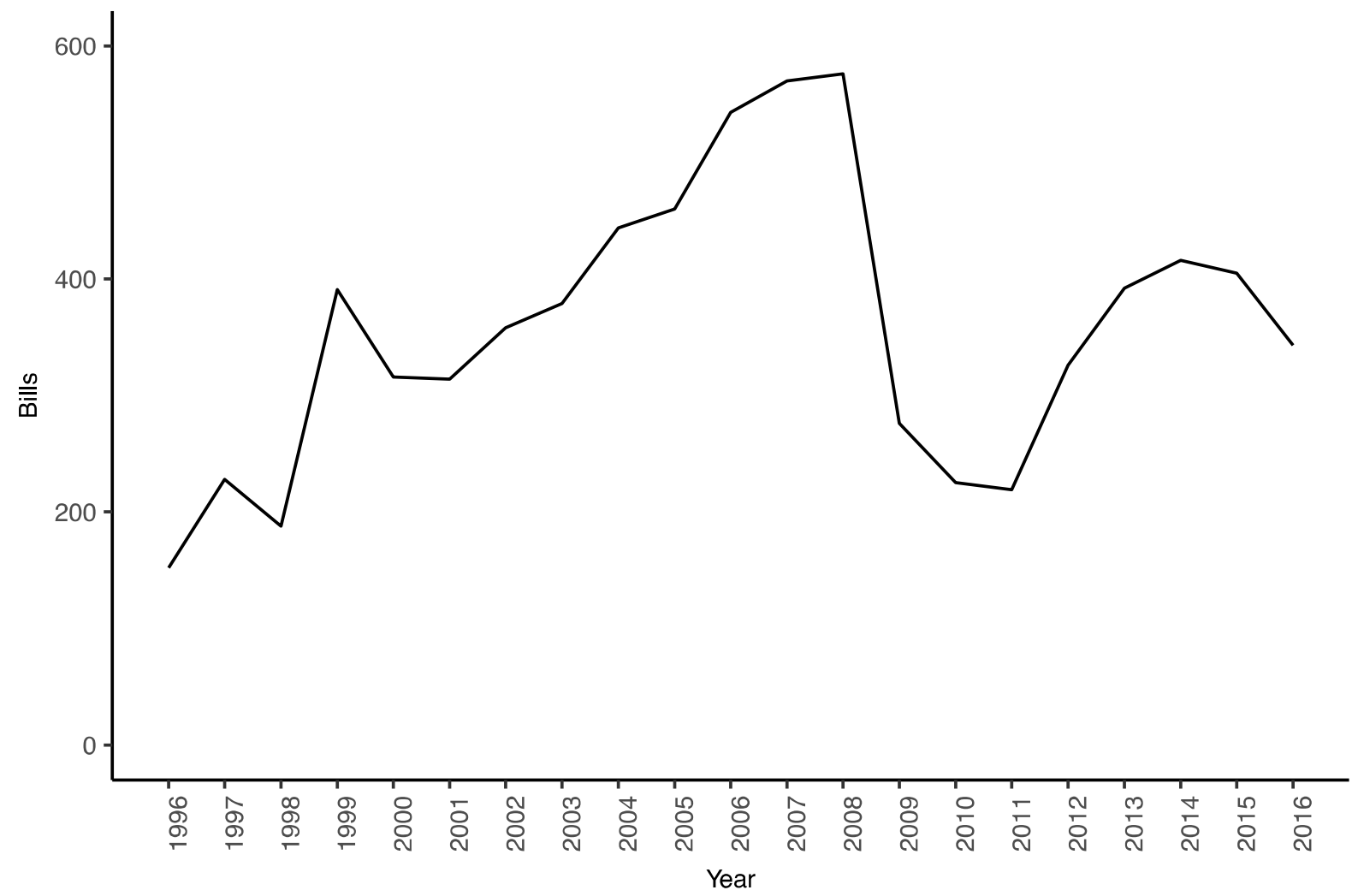

Notes: The data presented in this figure are taken from an original dataset (compiled by the author) of initiatives submitted into the Russian State Duma by regional assemblies (legislatures of federal subjects). ${ }^{4}$

${ }^{4}$ The author would like to thank Marsel Salikhov for help in compiling this dataset. 
Figure 2: Countries (in black) with constitutions giving sub-national legislatures the authority to introduce legislative bills into the national legislatures.

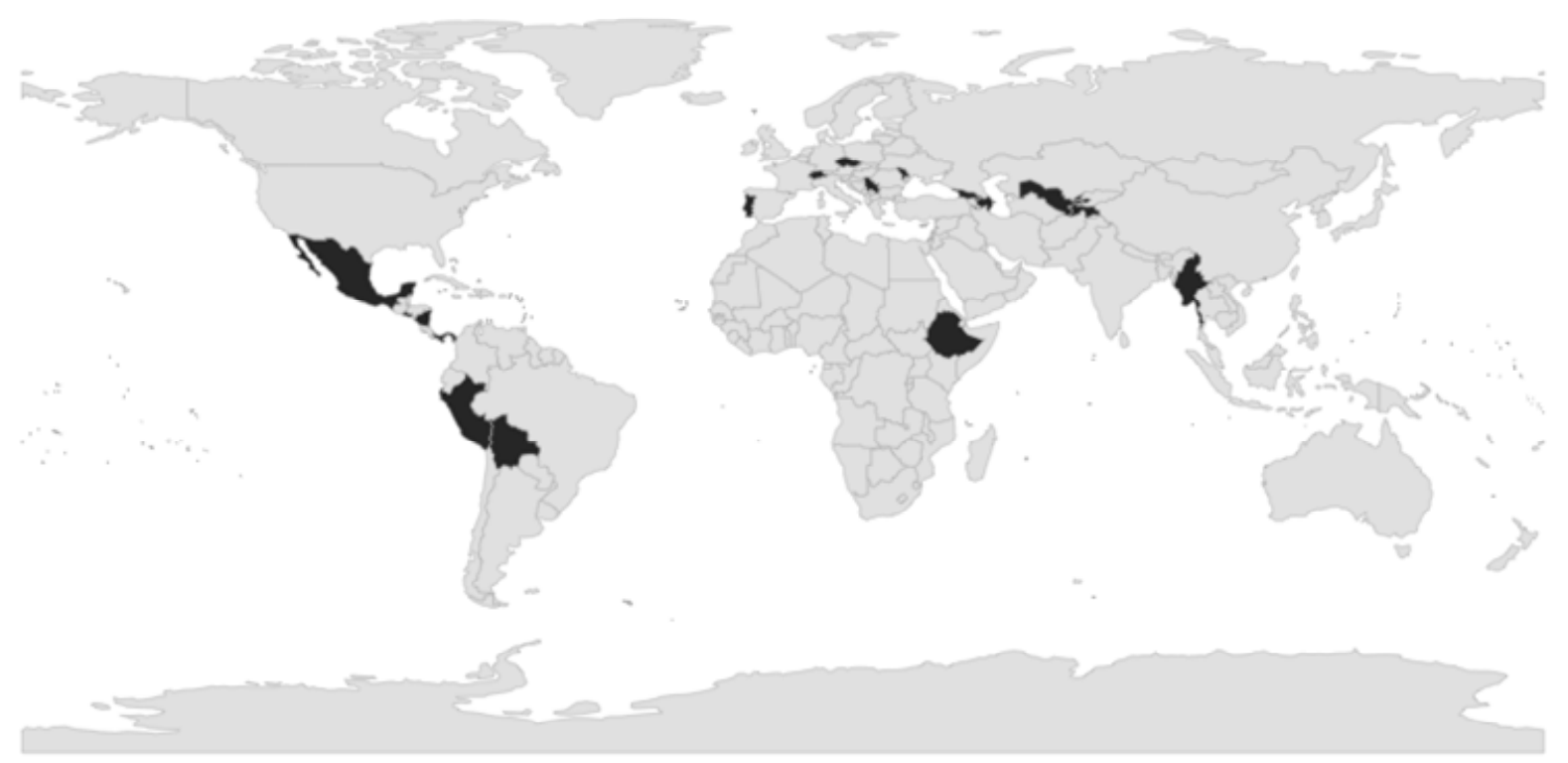

Notes: Data used to prepare this map are taken from the Comparative Constitutions Project dataset (Elkins, Ginsburg, and Melton, 2014). 


\section{References}

Downs, W. 2014. Sub-national legislatures. In S. Martin, T. Saalfeld \& K. Strøm (Eds.), The Oxford Handbook of Legislative Studies (pp. 609-627). Oxford: Oxford University Press.

Elkins, Z., T. Ginsburg, and J. Melton. 2014. Characteristics of National Constitutions, Version 2.0. http://comparativeconstitutionsproject.org/ccp-data-downloads/.

Noble, B., and E. Schulmann. 2018. 'Not Just a Rubber Stamp: Parliament and Lawmaking.' In D. Treisman (ed.), The New Autocracy: Information, Politics, and Policy in Putin's Russia. Washington, D.C.: Brookings Institution Press.

Ugues, A., D. Vidal, and S. Bowler. 2017. 'Los Congresos Estatales y la Política Federal en México: state legislatures and federal policymaking in Mexico.' The Journal of Legislative Studies', https://doi.org/10.1080/13572334.2017.1394740. 


\section{Acknowledgements}

This article is an output of the research project 'The influence of institutional factors on the regional structure of Russia's party system' carried out by the Laboratory of Regional Political Studies at the National Research University - Higher School of Economics, as part of the 2017 Annual Thematic Plan for Basic and Applied Research.

\section{Disclosure statement}

The author is unaware of any conflicts of interest.

\section{Biographical note}

Ben Noble is Lecturer in Russian Politics at University College London in the School of Slavonic and East European Studies. He was previously the Herbert Nicholas Junior Research Fellow in Politics at New College, University of Oxford. His research focuses on the legislative stage of lawmaking in non-democracies, with a particular focus on states of the former Soviet Union. 